\title{
LA ENSEÑANZA DE PRIMERAS LETRAS EN CHIAPAS EN LOS ALBORES DE LA INDEPENDENCIA, EN UN CONTEXTO IBEROAMERICANO
}

\author{
Morelos Torres Aguilar ${ }^{1}$ \\ Universidad Autónoma de Chiapas, México \\ Grupo de Investigación HISULA \\ morelostorres@gmail.com
}

Recepción: 30/04/2010

Evaluación: 28/06/2010

Aceptación:21/07/2010

Artículo de Reflexión

\section{RESUMEN}

El artículo es resultado de una investigación sobre la enseñanza de las primeras letras en Chiapas, en las postrimerías de la colonia y durante la revolución de independencia. El trabajo contextualiza y examina el discurso educativo del régimen colonial, y lo compara con esfuerzos similares que tuvieron lugar tanto en España como en otros países de Iberoamérica. A partir de las fuentes consultadas, se concluye que fracasaron los esfuerzos realizados por la corona española en cuanto a la enseñanza de primeras letras dirigida a la población en general.

Palabras clave:Enseñanza,Primeras Letras, Chiapas, Régimen Colonial, Independencia.

\footnotetext{
1 Doctor en historia por la Universidad Nacional Autónoma de México. Obtuvo mención honorífica y la medalla Alfonso Caso de esta institución por sus estudios de doctorado. Es profesor en el Doctorado en Estudios Regionales de la Universidad Autónoma de Chiapas, y coordinador regional del Seminario Nacional de Música de la Nueva España y el México Independiente [MUSICAT, UNAM / CONACYT]. Pertenece al Sistema Nacional de Investigadores de México.
}

Rhela. Vol. 14. Año 2010, pp. $139-168$ 


\title{
ELEMENTARY EDUCATIONAT THE DAWN OF THE INDEPENDENCE WITHIN AN IBERO- AMERICAN CONTEXT
}

\author{
Morelos Torres Aguilar \\ Universidad Autónoma de Chiapas, México \\ HISULA Research Group \\ morelostorres@gmail.com
}

\begin{abstract}
The article is the result of an investigation into the teaching of the first letters in Chiapas, in the aftermath of the colony and during the revolution of independence. The work contextualizes and examines the educational discourse of colonial regime, and compares it to similar efforts that took place in Spain and other countries in Latin America. Of the sources consulted, it concludes that they failed the efforts made by the Spanish Crown in teaching first letters addressed to the population in general.
\end{abstract}

Key words: Education, First Letters, Chiapas, Colonial Regime, Independence. 


\section{INTRODUCCIÓN}

Este trabajo precisa y desarrolla algunas líneas de generación del conocimientoque fueron propuestas, en años recientes, en sendas ponencias, como fundamento para una investigación de largo alcance. ${ }^{2} \mathrm{El}$ asunto central de estas líneas corresponde a la enseñanza de primeras letras en el territorio que corresponde al actual estado de Chiapas, en México, durante las últimas décadas del siglo XVIII y las primeras del siglo XIX.

La enseñanza de las primeras letras en Chiapas a fines del régimen colonial y a comienzos del México independiente es un tema relativamente nuevo dentro de la historiografía que ha sido escrita respecto al período. Si bien algunos autores han estudiado aspectos que se relacionan con el tema en forma colateral, no ha sido examinado en forma puntual el proceso mediante el cual fue introducida y transmitida la lengua castellana en el seno de una población mayoritariamente indígena, en la etapa final del régimen colonial y a comienzos del México independiente.

El primer problema planteado en el protocolo de la investigación, consiste en conocer cuál era la posición de la corona española respecto a la enseñanza de primeras letras en distintos territorios iberoamericanos, en particular en la Capitanía General de Guatemala, y específicamente en la alejada provincia de Chiapas, en los últimos años del siglo XVIII y en el primer cuarto del XIX.El segundo problema, que guarda una estrecha relación con el tema, es la existencia de iniciativas, generadas por diversos actores sociales, para transmitir la lengua castellana a una población predominantemente indígena, pues como se sabe, Chiapas constituía una de las regiones con mayor porcentaje de naturales en el ámbito de la Capitanía General de Guatemala.

El tercer problema que se presenta para estudiar el tema, es la relación que tuvo lugar en aquella época entre las tareas educativas y el desenvolvimiento de

\footnotetext{
2 TORRES AGUILAR, Morelos. (2008): "El discurso educativo de la corona española en las postrimerías de la Colonia en Chiapas",en Diálogos. Revista electrónica de Historia. San José. Universidad de Costa Rica - Escuela de Historia / Instituto Panamericano de Geografía e Historia. Número especial, IX Congreso Centroamericano de Historia, p. 1150-1162. Se puede consultar en http://historia.fcs.ucr.ac.cr/articulos/ 2008/especial2008/index.html. TORRES AGUILAR, Morelos. (2008):"Los ayuntamientos de Chiapas en el primer tramo del México independiente: el informe crítico de 1830". III Coloquio Internacional Migraciones y fronteras, San Cristóbal de las Casas, Chiapas, UNICACH-CESMECA / UNESCO / FLACSO Costa Rica. La investigación de largo alcance, que actualmente se encuentra en proceso, lleva por título "Aproximaciones a la historia de la educación en Chiapas: iniciativas pedagógicas en el siglo XIX”.
} 
la sociedad; y qué obstáculos se opusieron, en forma determinante, al desarrollo de las primeras.Por último, el cuarto problema consiste en conocer los resultados que tuvieron los proyectos de enseñanza en la región a fines del régimen colonial, y en los primeros años del Chiapas y del México independientes.

A partir de los problemas referidos, fueron delineados y planteados los siguientes objetivos:

1.Analizar el proyecto educativo ilustrado de la corona española a fines del siglo XVIII y comienzos del XIX, por medio del examen dediversas manifestaciones que tuvieron lugar en Iberoamérica en este sentido.

2.Describir algunos ejemplos de enseñanza de primeras letras que fueron desarrollados en la península ibérica en la misma época.

3.Describir algunos ejemplos de enseñanza de primeras letras que fueron desarrollados en las colonias americanas en la misma época.

4. Describir a grandes rasgos la situación social en la provincia de Chiapas.

5. Mostrar los principales rasgos de la acción educativa desarrollada en Chiapas por la Corona a fines del siglo XVIII y a principios del XIX.

6. Referir los trabajos desarrollados por la Corona en el campo de la enseñanza de primeras letras en Chiapas en los últimos años del régimen colonial.

7. Señalar los obstáculos que lentificaron o impidieron el desarrollo de la educación en Chiapas durante el período estudiado.

8. En las conclusiones, explicar el resultado que tuvieron las iniciativas de enseñanza en esta provincia, al finalizar un proceso de alrededor de medio siglo, y compararlo con los ejemplos iberoamericanos descritos.

Con el fin de responder en forma adecuada a la problemática planteada, y de cumplir apropiadamente los objetivos referidos, fue revisada cuidadosamente la escasa bibliografía específica en que se aborda el tema, la cual permitió contextualizar el proceso educativo, y aportó algunos elementos para dar respuesta al cuarto y quinto objetivos. ${ }^{3}$ Por otra parte, la consulta de un importante número de artículos relacionados con el tema permitió establecer un seguimiento adecuado respecto a los tres primeros objetivos.

Sin embargo, dado que la revisión bibliográfica resultaba insuficiente para profundizar en los objetivosplanteados, se hizo necesario e incluso indispensable

3 Entre las obras que abordan el tema se encuentran: FLORES RUIZ, Eduardo. (1978): La Catedral de San Cristóbal de las Casas. 1528-1978. Tuxtla Gutiérrez. Universidad Autónoma de Chiapas - Área de Humanidades. CARVALHO, Alma Margarita. (1994): La Ilustración del Despotismo en Chiapas, 1774-1821. México. Consejo Nacional para la Cultura y las Artes. SANTIAGO CRUZ, Francisco. (1977): Breve historia del Colegio de la Compañia de Jesús de Ciudad Real de Chiapas. México. Editorial Tradición. 
incluir, en el plan de trabajo, la revisión de los documentos que sobre el tema se encuentran en un archivo especializado. ${ }^{4}$ Cabe señalar aquí que los documentos encontrados permiten obtener una idea de la situación escolar en esta provincia en el período indicado. La revisión documental aportó una importante base de datos, la cual fue complementada con la información recabada en dos libros insoslayables para entender el proceso educativo de la época. ${ }^{5}$ Todos estos elementos permitieron conocer y describir las iniciativas de enseñanza elaboradas en la provincia en el período señalado, caracterizar el proceso de enseñanza de primeras letras que tuvo lugar en la región, y comparar éste con distintos procesos similares que tuvieron lugar en el ámbito iberoamericano de la época.

Por último, el análisis y la reflexión sobre los elementos antes señalados permitieron encontrar un conjunto de obstáculos que se opuso al desarrollo de los proyectos educativos del régimen colonial y de la naciente república, y que resultó de tal magnitud, que determinó el fracaso del proceso educativo en Chiapas durante la primera década del México independiente.De esta manera, se aplicó el método comparativo para el análisis de las experiencias educativas que tuvieron lugar sobre la materia en distintas regiones de Iberoamérica en el período explorado. Y asimismo, se realizaron ejercicios de análisis de discurso y de análisis sociohistórico con el fin de encontrar explicaciones a los principales obstáculos que impidieron el cumplimiento de los proyectos educativos descritos a lo largo del trabajo.

Finalmente, en las conclusiones se realizan una síntesis y una interpretación de los principales elementos resultantes del análisis efectuado en cada uno de los objetivos.

\section{Rasgos Ilustrados en el Proyecto Educativo de la Corona Española a Fines del Siglo XVIII y a Comienzos Del XIX}

En la segunda mitad del siglo XVIII, la educación en los territorios dependientes de la Corona española tomó un impulso notable, a partir de la iniciativa de diversos pensadores de mentalidad reformista, cuyas ideas se relacionaban con el pensamiento ilustrado de la época, y cuyas relaciones les

\footnotetext{
4 Se trata del Archivo Histórico Diocesano de San Cristóbal de las Casas (AHDSCLC), ubicado en la ciudad del mismo nombre, en el estado de Chiapas, México.

5 OROZCO Y JIMÉNEZ, Francisco. (1999): Documentos Inéditos de la Historia de la Iglesia en Chiapas. Tuxtla Gutiérrez. Gobierno del Estado de Chiapas / Consejo Estatal para la Cultura y las Artes de Chiapas. Tomos I y II. TRENS, Manuel B. (1999): Historia de Chiapas. Desde los tiempos más remotos hasta la caída del Segundo Imperio (¿...1867?). Tuxtla Gutiérrez, Consejo Estatal para la Cultura y las Artes de Chiapas - Libros de Chiapas. Tomos I y II.
} 
posibilitaban influir en las decisiones gubernamentales. En este sentido, los proyectos de los condes de Campomanes y Cabarrús, así como de Gaspar Melchor de Jovellanos, proponían lograr "una enseñanza nacional uniforme para los distintos niveles, tanto en lo que se refiere a métodos, libros y disciplina", así como fundar nuevos establecimientos, que sustituyeran "en parte a la multiplicidad de los ya existentes",a través de los cuales se habrían de propagar los nuevos valores, y se habrían de transmitir"conocimientos, habilidades y hábitos acordes con la nueva visión del mundo ilustrada." 6

En cuanto a la enseñanza de las primeras letras, los ilustrados españoles proponían la creación de unas "escuelas patrióticas y populares", caracterizadas por una educación "elemental, de primeros principios y rudimentos", con fines claramente moralizantes. Más allá de la originalidad de la propuesta, la segunda mitad del siglo XIX se caracterizó en la península por una gran variedad de escuelas de enseñanza elemental: "escuelas caritativas de los hospicios, escuelas patrióticas, escuelas de primeras letras de la Hermandad de San Casiano, escuelas de las Diputaciones de Barrio, colegios de órdenes religiosas y especialmente de los Hermanos de las Escuelas Pías."

Resulta importante mencionar que éstos últimos, los escolapios, fundaron durante los siglos XVII y XVIII numerosas escuelas gratuitas en la península, pues sus constituciones les obligaban a ello. En apego a dicho precepto, "las dos órdenes de la Contrarreforma con más empuje se repartieron del siguiente modo el terreno: para los escolapios la doctrina y las primeras letras, para los jesuitas los colegios de gramática, determinados colegios mayores, ciertas universidades y los colegios de nobles." ${ }^{\prime}$

El proyecto ilustrado se materializó en las "escuelas patrióticas", así como en escuelas de primeras letras y escuelas de oficios, todas ellas fundadas por las Sociedades Económicas de Amigos del País. En particular, las primeras sirvieron como modelo "para la educación de los hijos de los pobres", el cual fue seguido, por ejemplo, por las Diputaciones de Barrio para fundar sus propios establecimientos educativos.Es importante resaltar en España, durante la segunda mitad del siglo XVIII, el desarrollo de una corriente ilustrada que, como lo escribía Manuel José Narganes, postulaba la necesidad de secularizar la

\footnotetext{
6 VARELA FERNÁNDEZ, Julia. (1988): "La educación ilustrada, o cómo fabricar sujetos dóciles y útiles”, en Revista de Educación. Madrid. Ministerio de Educación. No. Extra 1. p. 261

7 Ibídem. p. 267

8 Ibídem. p. 266.
} 
enseñanza, arrebatando esta importante tarea de manos de la Iglesia, y de obligar a ésta a sujetarse a las leyes, pues consideraba que la instrucción pública era un asunto que, "por derecho y obligación", atañía al gobierno, el cual por ello debía "ejercer su dirección, inspección y control."”

En este sentido, en algunas ordenanzas, como la Provisión del 21 de octubre de 1767, en Cataluña, se manifiesta la conveniencia de que la enseñanza "estuviese en manos de maestros laicos y no de órdenes religiosas"; sin embargo, esta idea resultó inaplicable en muchos casos, debido a que contratar profesores laicos resultaba más costoso para los municipios. Además, los mentores religiosos ofrecían varias ventajas sobre ellos, pues no había que pagarles, ya que disponían de sus propias rentas y beneficios; representaban un gasto menor, al no tener familia; mostraban con frecuencia una formación más sólida que la de los laicos; y además, por su naturaleza, proporcionaban una educación moral y religiosa acorde con aquello que la sociedad esperaba de un profesor. ${ }^{10}$

Como se sabe, la expulsión de los jesuitas de los dominios de España en 1767 constituyó un hecho determinante para el destino de la educación iberoamericana. Por una parte, el hecho cesó de manera abrupta la fundación de nuevos colegios, e impidió el funcionamiento apropiado decentros escolares de distintos niveles;por otra, la partida de cientos de importantes profesores jesuitas, con la consiguiente clausura de escuelas, obligó a que la corona replanteara en forma urgentesu proyecto educativo.

En el caso de las escuelas de primeras letras de la península, tal reorganizaciónpropició el fortalecimientolos escolapios, quienes se volvieron muy importantes para el desempeño de la obra educativa planeada por los monarcas borbones. Dicha orden, fundadora de escuelas pías, presentaba ventajas notables respecto a otras que educaban en la misma época: contaba con "un sistema uniforme de enseñanza", disponía de un cuerpo de profesores ya formado, había fijado un solo tipo de letra como base de la enseñanza -la llamada escolapia o bastarda-, enseñaba el castellano en todas sus clases, y sobre todo, cubría con eficacia las necesidades del gobierno ilustrado. ${ }^{11}$

9 DELGADO CRIADO, Buenaventura (Coord.). (1994): Historia de la educación en España y América. Volumen 3. La educación en la España contemporánea (17891975). Madrid. Ediciones SM / Fundación Santa María. p. 73.

${ }^{10}$ BURGOS RINCÓN, Javier. (1994): "Alfabetización y escuela en Cataluña en el Siglo de las Luces. Una hipótesis interpretativa”, en Manuscrits. Revista d'Història Moderna. Barcelona. Universitat Autónoma de Barcelona. No. 12. Gener. pp. 134.

${ }^{11}$ VARELA FERNÁNDEZ, Julia. óp. cit. p. 267. 


\section{La Enseñanza de Primeras Letras en la Península Ibérica a fines del Siglo XVIII y a principios del XIX. Algunos ejemplos}

Debemos a Ventajas Dote una clasificación muy útilpara apreciar las distintas modalidades de la instrucción elemental en el siglo XVII en la península. En términos generales, dice este autor, en la España de mediados del siglo XVIII la enseñanza de primeras letras era impartida mediante varias modalidades: maestros particulares (en su mayoría clérigos) que enseñaban en los propios hogares de los alumnos, principalmente de clases acomodadas; escuelas públicas, abiertas a todos los alumnos, pero no gratuitas; instituciones benéfico-docentes gratuitas, mantenidas por los poderes estatales, municipales o por la Iglesia; y colegios anejos a los conventos (dependientes de las órdenes religiosas, donde destacaron los jesuitas, franciscanos, carmelitas, agustinos y escolapios), que estaban libres de todo control regio y en los que la enseñanza solía ser gratuita. ${ }^{12}$

Pese a la existencia de todas estas posibilidades, "evidentemente mayores en las grandes ciudades que en las zonas rurales, donde muchas veces se reducían a la labor realizada por los párrocos", ${ }^{13}$ se puede apreciar la falta de instrucción de la mayor parte de la población española, en la cual el grado de analfabetismo era superior al $90 \%$, con menos de una cuarta parte de los niños escolarizados.

En este marco puede ser entendidoel caso de Cataluña, donde tras la expulsión de las jesuitas fueron abiertas escuelas gratuitas de primeras letras en diez conventos, por iniciativa del obispo Josep Climent, en contraposición a "la Real Cédula del 5de marzo, que pretendía impulsar la secularización del magisterio de primeras letras." ${ }^{14}$ La razón por la cual la Iglesia prosiguió al frente de estos establecimientos era el mal estado de las finanzas locales. Aunque dichas escuelas fueron cerradas en 1771 por recomendación de la Junta de Gobierno, con el argumento de que no ocupaban sus aulas los niños de las familias pobres, reiniciaron sus actividades en la gestión del obispo Asensio Sales, sucesor de Climent, debido a que "cubrían una parte de las necesidades de escolarización sin suponer ningún gasto a las arcas públicas," 15 si bien resultaban insuficientes para atender a los niños en edad escolar, como lo señala

\footnotetext{
12 Ventajas DOTE, Fernando. (2000): “La enseñanza en Málaga en tiempos de Fernando VI (1746-1759)", en Revista Jábega. Málaga, Centro de Ediciones de la Diputación de Málaga. No. 84. p. 27.

13 Ibídem. P, 45.

14 BURGOS RINCÓN, Javier. óp. cit. p. 116.

${ }^{15}$ Ibídem, p 67.
} 
Morelos Torres Aguilar

Burgos Rincón.De este modo, en Terrassa, una pequeña ciudad cercana a Barcelona, durante la primera mitad del siglo XVIII no existía una escuela de primeras letras, cuya enseñanza sólo quedaba en manos del cura de la localidad. Parece que la situación varió hacia fines del siglo, con la decisión del ayuntamiento de elegir un maestro de primeras letras, y más adelante, en 1800, con la fundación incluso de un "establecimiento pío de la enseñanza de donzellas o mujeres." ${ }^{16}$ Sobre este mismo particular, destaca Nava Rodríguez queen tiempos de Carlos III, en 1776, funcionaban en Madrid cuatro escuelas gratuitas que conocidas con el nombre de "patrióticas",y que dirigidas por la Sociedad Económica Matritense, se orientaron pronto a la educación de niñas. En ellas no sólo se enseñaba a las alumnas a leer, escribir y contar, sino también a hilar, tejer y bordar. ${ }^{17}$

Por su parte Tentudia, una comarca de Extremadura, muestra a fines del siglo XVIII serias deficiencias en la enseñanza. Gutiérrez Barba menciona que ésta se efectuaba en locales pequeños, en mal estado, insalubres; además, que era muy escasa la asistencia de los escolares, "por razones económicas, bien por la necesidad de realización de labores agrarias, o bien por la desidia de los padres". Y si este fenómeno de daba incluso a edades tempranas, "en las últimas edades el absentismo escolar era generalizado". Asimismo los maestros no solían tener la preparación adecuada, "debido a los bajos salarios que se reciben, por lo que la enseñanza queda relegada para ellos a un plano secundario."18

Garrido Díaz señala que a fines del siglo XVIII "la realidad extremeña ofrecía deficiencias en maestros, carencias en escuelas y pobres iniciativas de los municipios". A pesar de que la Real Provisión de 1771 establecía que la enseñanza habría de estar a cargo de maestros de primeras letras que cubrieran los requisitos estipulados en la norma, "existe constancia del desempeño de estas funciones por parte de muchas personas que carecían de dicho título... clérigos, sacristanes, médicos, escribanos, oficiales del ejército, etc.”19 En la

\footnotetext{
${ }^{16}$ FERNÁNDEZ, María Luisa. (2009) "L’Alfabetitizació i ensenyament de primeres lletres a Terrassa durant el segle XVIII", en Revista HMiC. Barcelona. Universitat Autònoma de Barcelona. No. 7. p. 43.

${ }^{17}$ NAVA RODRÍGUEZ, Teresa. (1995): "La mujer en las aulas (siglos XVI-XVIII): una historia en construcción", en Cuadernos de Historia Moderna. Madrid. Servicio de Publicaciones UCM. No. 16. pp. 383.

18 GUTIÉRREZ BARBA, Alfonso. (2001): "Situación de la enseñanza de primeras letras en la comarca de Tentudía entre mediados del siglo XVIII y mediados del XIX", en Actas del I Congreso de la Memoria Colectiva de Tentudía. Badajoz. Centro de Desarrollo Comarcal de Tentudía. p. 455.

${ }^{19}$ GARRIDO DÍAZ, María del Pilar. (2000): "Un método de enseñanza a principios del siglo XIX en la escuela rural de la Baja Extremadura: contexto y pretexto para su estudio", en Revista de Estudios Extremeños. Badajoz. Vol. 56. No. 3. p. 1113.
} 
Extremadura de fin de siglo se repiten los problemas existentes en otras provincias ibéricas: los profesores reciben bajos salarios, los alumnos no asisten a las clases, los recursos no alcanzan. En este contexto, resulta sumamente meritoria la aplicación en Montemolín -un pueblo de la región- de un método de enseñanza de la lectura "que se acostumbraba en las Escuelas Pías de Madrid,"20 y que obtuvo buenos resultados en unos cuantos años.

En cuanto al caso de Navarra, Laspalas señala que en la segunda mitad del siglo XVIII las escuelas de primeras letras "estaban en manos de la administración local, y la intervención del Real Consejo era escasa." ${ }^{21}$ Es decir, los municipios se hacían cargo de las escuelas, sin que el Estado interviniera de manera determinante en la materia. Sólo tras la creación de la Junta Superior de Educación, ya en el siglo XIX, y con la elaboración del Plan y Reglamento para las Escuelas de Primeras Letras de Navarra, en 1831, el gobierno central habría de controlar la enseñanza, mediante la avanzada idea de instrucción pública.Como en otras provincias, los profesores navarros podían desempeñar un segundo oficio, por ejemplo el de sacristán, organista, escribano, notario o agrimensor. Sin embargo, lo más interesante en el caso de Navarra es que la iglesia sólo colaboraba de forma indirecta en la enseñanza, siendo los municipios los principales impulsores de la educación pública.

En la provincia de La Mancha la situación no era distinta. En Villanueva de los Infantes, por ejemplo, uno de los poblados más importantes, el reglamento establecía que los maestros no podían dedicarse a otra actividad que la enseñanza, ya que se consideraba que el segundo empleo les distraería de su trabajo docente. Asimismo, mientras que los hijos de los pobres no pagaban por su instrucción, los hijos de los más ricos debían pagar 9 reales mensuales. Sin embargo, a veces dicho reglamento no podía ser aplicado, pues la mayoría de los niños abandonaban las aulas para realizar trabajos agrícolas de temporal, o bien lo hacían cuando faltaban todo el mes de agosto o se enfermaban, y en esas ocasiones los maestros no recibían parte de su salario. Por eso el maestro Benito de Vargas, por ejemplo, terminó por redondear sus ingresos con una segunda profesión, la de tendero. ${ }^{22}$

\footnotetext{
${ }^{20}$ Ibídem. p. 1116.

${ }^{21}$ LASPALAS PÉREZ, Javier. (2002): "La legislación sobre escuelas de primeras letras y su administración en Navarra durante la segunda mitad del siglo XVIII", en Educación XXI: Revista de la Facultad de Educación. Madrid. Universidad Nacional de Educación a Distancia-Facultad de Educación. No. 5. p. 208.

22 ASENSIO RUBIO, Francisco. (2002): "La educación en Almagro en el siglo XVIII", en Espacio, Tiempo y Forma. Madrid. Universidad Nacional de Educación a DistanciaFacultad de Geografía e Historia. Serie IV. Historia Moderna. No. 15. p. 274.
} 
En otras poblaciones de La Mancha la situación era todavía peor; en algunas como Alcubilla, Fuenllana, Cózar, Villahermosa, Montiel, Cañamares o Alhambra no había maestro alguno, y en otras un solo maestro atendía a los hijos de 200, 300 o 400 vecinos. En todo caso, los profesores enseñaban en un entorno de extrema pobreza. Además, la calidad de la educación dejaba mucho que desear, cuando educación había. En Almagro, por ejemplo, en la segunda mitad del siglo XVIII terminaron por incorporarse a la enseñanza de las primeras letras un barbero, un carpintero-retablero y un sastre, quienes sólo tuvieron que aprobar un examen ante el ayuntamiento para ejercer la docencia. ${ }^{23} \mathrm{Y}$ aunque fueron promovidos numerosos juicios y libradas varias órdenes para que los maestros sin título lo obtuvieran, o bien dejaran de impartir clases, la realidad es que todavía en los últimos años del siglo algunos profesores seguían ejerciendo la docencia en forma irregular, e incluso empleaban a sus alumnos en trabajos de albañilería, o para conseguir la comida de los animales de corral. ${ }^{24}$

En suma, la enseñanza elemental en España en la segunda mitad del siglo XVIII presentaba problemas de difícil solución: muchas poblaciones no contaban con escuelas, no había una financiación adecuada para el ramo educativo por parte del Estado, los maestros recibían un salario insuficiente, o bien la calidad de la enseñanza era deficiente.La enseñanza de primeras letras constaba del aprendizaje de la lectura, la escritura, el cálculo aritmético elemental y la doctrina cristiana. La edad escolar de los niños solía comenzar entre los seis y los siete años; pero en vista de que la asistencia a clases no era obligatoria, los alumnos se ausentaban con frecuencia "por razones de trabajo, pobreza o negligencia paterna, sobre todo en las escuelas públicas, máxime cuando la actividad laboral de la población no necesitaba de los conocimientos que se adquirían en ese nivel educativo. $" 25$

Además, en la época estudiada, la profesión de maestro de primeras letras no resultaba muy atractiva en la península. Por lo general, se exigía que los mentores tuvieran un título profesional, expedido por autoridades en la materia, como la Hermandad de San Casiano;que mostraran un certificado donde se acreditara su buena conducta y una preparación suficiente en la doctrina cristiana; y que demostraran experiencia docente. Pero la compensación por estos esfuerzos resultaba poco satisfactoria: se trataba de un oficio mal pagado, y que no ofrecía gran prestigio social. ${ }^{26}$ En ocasiones, los profesores recibían un

\footnotetext{
${ }^{23}$ Ibídem. p. 279.

${ }^{24}$ Ibídem. p. 287.

${ }^{25}$ VENTAJAS DOTE, Fernando. óp. cit. p. 28.

${ }^{26}$ FERNÁNDEZ, María Lluisa. óp. cit. p. 42.
} 
salario tan reducido, que debían tener al mismo tiempo alguna otra profesión u oficio para completar sus ingresos, con el consiguiente deterioro en la calidad de la enseñanza. ${ }^{27}$

Aunque, como advierte López Domenech, resulta muy peligroso hacer visiones generales, pues "dentro de la misma comarca las diferencias entre los pueblos eran muy grandes, y en muchos casos debían responder a criterios arbitrarios", ${ }^{28}$ las características descritas de la educación en España permiten establecer un marco contextual apropiado para comparar la situación de la enseñanza en Chiapas en la misma época.

\section{La Enseñanza de Primeras Letras en Latinoamérica a fines del Siglo XVIII y a principios del XIX. Algunos ejemplos}

Resulta sumamente difícil establecer algunas directrices generales para la instrucción elemental en el enorme ámbito de las colonias españolas en América, en el período estudiado. Sin embargo, resulta revelador el estudio de algunos ejemplos.

Silva encuentra en el Virreinato de Nueva Granada, a fines del siglo XVIII, seis formas de alfabetización (la cual comprendía la enseñanza de la lectura y la escritura). La primera fue emprendida por la Iglesia, quien enseñaba y evangelizaba mediante sus escuelas parroquiales y escuelas doctrinales. Dentro de esta forma destaca la tarea alfabetizadora de la Compañía de Jesús, la cual tenía escuelas para niños en Santafé y Popayán, así como en todos sus colegios, según se menciona en sus documentos. La segunda, si bien infrecuente, fue posible gracias a las donaciones intervivos y testamentarias, pues algunas personas legaron importantes sumas para el sostenimiento de una escuela, es decir del maestro a cargo de la instrucción elemental.

La tercera fuente de alfabetización la constituían las acciones de "las familias notables y distinguidas", las cuales se esforzaban para que sus hijos adquirieran la capacidad de leer, de escribir y contar. La cuarta provino de "los preceptores privados", los cuales se encargaban de enseñar lectura y escritura a la descendencia joven de sus patronos. En quinto lugar se hallaban los talleres artesanales, los cuales supusieron una nueva forma de acceso a la lectura e

\footnotetext{
27 GUTIÉRREZ BARBA, Alfonso. óp. cit. p. 450.

${ }^{28}$ LÓPEZ DOMECH, Ramón. (2000): "La viga de Ohanes: algo más que un conflicto escolar en el siglo XVIII", en Revista Complutense de Educación. Madrid. Universidad Complutense. Vol. 11. No. 1. p. 173.
} 
incluso a la escritura, ya que los artesanos se hallaban entre los grupos más cercanos a la cultura escrita. Por último, la sexta forma de alfabetización la constituían los maestros ambulantes, "hombres pobres despojados de toda propiedad inmueble, con un nivel cultural mínimo (reducido a la lectura, la escritura y un poco de latín), quienes en su propia vivienda abrían escuela con un permiso temporal de los funcionarios locales, o bien sin autorización alguna." ${ }^{29}$

En Nueva Granada se puede apreciar el intento que hizo la Corona de restablecer e incluso renovar la antigua red de escuelas y colegios que había quedado huérfana tras la expulsión de los jesuitas. Sin embargo, al parecer entre 1770 y 1790 "difícilmente se logró alcanzar siquiera el reducido número de escuelas de niños que existía antes de la expulsión”. Sólo en los últimos años del siglo, las medidas del virrey José de Ezpeleta se orientaron a la fundación, por parte de los municipios, de por lo menos una escuela en cada población. ${ }^{30}$ De cualquier modo, la proliferación de planes para fundar escuelas a fines del siglo XVIII constituye un hecho notable en la historia de este virreinato.

En cuanto al caso panameño en el mismo período, escribe Méndez Pereira:

Fuera de los centros conventuales, hasta los cuales no llegaban las clases bajas, sólo existía una que otra escuela privada, regentada, en lo general, por personas de escasisima instrucción: curas de parroquia, religiosos legos o maestros españoles, que enseñaban también a domicilio los primeros rudimentos y la doctrina cristiana. Los alumnos no sólo debían llevar a la escuela los libros y útiles de estudio, sino también el pobre banco o silla que les servía de asiento en clase y debían pagar al maestro un pequeño emolumento, que venía a aumentar su renta misérrima. Los conocimientos científicos se limitaban a las cuatro operaciones fundamentales de la aritmética, y la enseñanza misma era puramente mecánica. No se conocían métodos ni procedimientos pedagógicos, y el sistema de enseñanza consistía en el ejercicio continuo de la memoria. ${ }^{31}$

Más al norte, la Nueva España vivió en el siglo XVIII un complejo proceso de castellanización que debió enfrentar un considerable e histórico rezago en la materia. Como recuerda Tanck de Estrada, tras la conquista el fin primordial había sido instruir a los indígenas en la fe católica, y para ello la instrucción

\footnotetext{
${ }^{29}$ SILVA, Renán. (2008): "Alfabetización, cultura y sociedad. La experiencia del siglo XVIII en el Virreinato de Nueva Granada". Citado como autor invitado en la revista Historia Crítica. Colombia. Universidad de los Andes. p. 25.

${ }^{30}$ SILVA, Renán. óp. cit. p. 29.

${ }^{31}$ MÉNDEZ PEREIRA, Octavio. (1999): Historia de la Instrucción Pública en Panamá.

Panamá. Autoridad del Canal de Panamá. p. 272.
} 
religiosa fue impartida en los idiomas nativos, generalmente por los frailes criollos y sus ayudantes indígenas. Así que, cuando a mediados del siglo XVIII se promovió el establecimiento de escuelas de castellano en los pueblos de indios, cuyos maestros serían pagados con fondos de los propios indígenas, guardados en las cajas de comunidad, éstos se opusieron a la medida, porque "se resistían a enviar a sus hijos para aprender una lengua que consideraban extraña y difícil." ${ }^{2} 2$

A pesar de lo anterior, en algunos años se fundaron 286 escuelas en 76 pueblos de indios, pertenecientes al Arzobispado de México, y por lo menos en una cuarta parte de ellas se enseñaba a leer y escribir. Tras la expulsión de los jesuitas, el arzobispo Lorenzana propuso que no sólo se enseñara el castellano, sino que también se desterraran las lenguas indígenas, con el siguiente argumento: "El mantener el idioma de los indios es mantener en el pecho un ascua de fuego, un fomento de discordia y una piedra de escándalo, para que se miren con aversión entre sí los vasallos de un mismo soberano". Por ello, basado en la pastoral del arzobispo, Carlos III expidió en 1770 una cédula en la que pedía: "que de una vez se llegue a conseguir el que se extingan los diferentes idiomas de que se usa en los mismos dominios y sólo se hable el castellano." ${ }^{33}$

Este mismo proceso fue vivido también en Centroamérica, en la Capitanía General de Guatemala, y en particular en las provincias de San Salvador y Sonsonate. Al igual que en la Nueva España, en éstas, como lo señala Alfredo Herrera, desde el siglo XVI la educación había sido instrumentada por las órdenes regulares, que enseñaban la doctrina cristiana, a leer y escribir, pero en la lengua de los naturales. La respuesta de la Corona consistió en consentir el trabajo de las órdenes, disponiendo que los indígenas aprendiesen el castellano por su libre voluntad. Sin embargo, en los siglos siguientes, la Corona recibió diversas sugerencias y recomendaciones de autoridades civiles y eclesiásticas, que destacaban la necesidad de contar con indios castellanizados, ya que las lenguas nativas eran un obstáculo para la comprensión de los misterios de la fe cristiana. Así, en la década de los 50 del siglo XVIII la Corona inició un proyecto de castellanización de los indios, conocido como la secularización de las doctrinas. ${ }^{34}$

\footnotetext{
32 TANCK DE ESTRADA, Dorothy. (1996): "Enseñanza y nacionalismo intelectual al final de la colonia", en BAZANT, Milada (Coord.): Ideas, valores y tradiciones. Ensayos sobre historia de la educación en México. México. El Colegio Mexiquense. p. 82.

33 TANCK DE ESTRADA, Dorothy. óp. cit. p. 83.

${ }^{34}$ ALFREDO HERRERA, Sajid. (2007): "Primary Education in Bourbon San Salvador and Sonsonate, 1750-1808", en DYM, Jordana; BELAUBRE, Christophe (Coord.) Politics, economy, and society in Bourbon Central America, 1759-1821. University Press of Colorado. p. 20.
} 
Morelos Torres Aguilar

Este proyecto ordenaba poner en manos del clero secular, y ya no en las órdenes regulares, la educación de los indios. Sin embargo, el discurso oficial se fue atenuando, sobre todo cuando enfrentó la oposición de los naturales. De este modo, en 1754 el rey Fernando VI pedía que les fuera enseñado el castellano a éstos, pero de manera moderada y suave. Y más adelante, en 1757, no sólo aclaraba que el clero secular ocuparía únicamente aquellas plazas de maestro que quedaran vacantes, sino que obligaba a los nuevos profesores a conocer las lenguas de los indígenas. ${ }^{35}$

Con el ascenso al trono de Carlos III, la castellanización cobró nuevos ímpetus. La Real Cédula de 16 de abril de 1770 ordenaba hacer "único y universal" el castellano en los territorios coloniales, y las Ordenanzas de intendentes para la Nueva España de 1786, utilizadas en Guatemala, ordenaban que los subdelegados indujeran a los indios a hablar el castellano. ${ }^{36}$

En la provincia de Yucatán -perteneciente a la Nueva España-, a comienzos del siglo XIX, las escuelas de primeras letras contaban con un importante precedente. A fines del siglo XVII, el obispo Juan Cano de Sandoval había ordenado que en todo el obispado los curas establecieran escuelas parroquiales en beneficio de los jóvenes, "especialmente de los indios, a quienes debía no sólo enseñárseles la doctrina cristiana, como se venía haciendo, sino también los elementos de lectura y escritura" en castellano. ${ }^{37}$ Sin embargo, a mediados del siglo XVIII tales escuelas habían decaído por varias causas, entre ellas las dificultades que tenían los indios para enviar a sus hijos diariamente, y la codicia de los patrones (encomenderos y funcionarios públicos), quienes por salvaguardar sus ganancias, solían disminuir las horas de que podían disponer los jóvenes indígenas para el estudio.

En apoyo a la castellanización, la Real Cédula de 17 de abril de 1789 ordenaba "el establecimiento de escuelas de idioma castellano en todos los pueblos de indios para que en ellas aprendan a leerle, escribirle y hablarle, prohibiéndoles usar de su lengua nativa, y señalando para ello maestros". Sin embargo, la orden no tuvo éxito. El mismo año, fray Adrián Aldave describe la postura de los indígenas yucatecos ante la enseñanza: "como no reconocen subordinación, no quieren ni han querido mandar a sus hijos a la escuela... por

\footnotetext{
${ }^{35}$ ALFREDO HERRERA, Sajid. óp. cit. p. 21.

${ }^{36}$ ALFREDO HERRERA, Sajid. óp. cit. p. 26

37 SANTIAGO PACHECO, Edgar A.; CÁMARA GUTIÉRREZ, Guadalupe; KOECHERT, Andreas. (2005): "La educación en la provincia de Yucatán a fines del siglo XVIII y a principios del XIX", en Ketzalcalli. No. 2. p. 122.
} 
cuyo motivo no hay maestro de escuela, pues el que había hizo renuncia por ver que no asistían los niños, ni había quien obligue a los padres a mandarlos." ${ }^{\text {38 }}$

En este mismo sentido, el párroco de Conkal, fray Francisco Sánchez y Gálvez, expresa en su testimonio que los feligreses indígenas no hablan, pero tampoco quieren hablar el castellano; que tampoco quieren que sus hijos vayan a la escuela, pues "responden que para qué han de aprender sus hijos si siempre han de ser lo que son, y no dejarán de ser tristes indios, y que los necesitan para que les ayuden en sus trabajos". Del mismo modo fray Manuel Torres, asignado a Cenotillo, expresa su fracaso: "los indios no saben castellano, y por más que he insistido a sus padres los entreguen a las escuelas para aprenderlo, como aprenden la doctrina cristiana, no he podido obligarlos." ${ }^{\text {39 }}$

En suma, Pacheco, Cámara y Koechert señalan las dificultades que tenían que enfrentar los curas y frailes en Yucatán para establecer y mantener sus escuelas: falta de infraestructura física, escasez económica, falta de maestros, $\mathrm{y}$ finalmente la negativa de los indígenas a instruirse. ${ }^{40}$

\section{Ciudad Real en la Capitanía General de Guatemala a principios del Siglo XIX}

Hacia fines del siglo XVIII y principios del XIX, Ciudad Real -hoy llamada San Cristóbal de las Casas- era una de las doce ciudades que se hallaban en la Capitanía General de Guatemala. Capital de la intendencia del mismo nombre, que colindaba con el Virreinato de la Nueva España, se caracterizaba tanto por su aislamiento como por el escaso número de sus habitantes. Si según el censo de 1778, en toda la provincia había 78,596 habitantes, en Ciudad Realsólo se asentaban poco más de seis mil. ${ }^{41}$

La Capitanía estaba compuesta por quince provincias, que comprendían cuatro intendencias, veintinueve subdelegaciones, cuatro distritos políticomilitares, tres corregimientos y siete alcaldías. ${ }^{42}$ Entre las doce ciudades que

\footnotetext{
38 SANTIAGO PACHECO, Edgar A.; CÁMARA GUTIÉRREZ, Guadalupe; KOECHERT, Andreas. óp. cit. p. 124

39 SANTIAGO PACHECO, Edgar A.; CÁMARA GUTIÉRREZ, Guadalupe; KOECHERT, Andreas. óp. cit. p. 123.

${ }^{40}$ Ibídem. Por ejemplo, en pueblos como Tekax un solo maestro servía a "500 indios y 500 vecinos".

41 POLANCO, Francisco. (1999): "Estadística de Chiapas, 1776", en OROZCO Y JIMÉNEZ, Francisco, óp. cit. T. II, p. 67.

42 SALAZAR, Ramón A. (1988): "La Capitanía General de Guatemala. Su organización", en COLLADO, Carmen; DUTRÉNIT, Silvia, et al, Centroamérica I. México. Secretaría de Educación Pública / Instituto Mora / Universidad de Guadalajara.p. 99.
} 
Morelos Torres Aguilar

habían sido fundadas en la nación colonial destacaba, precisamente, Guatemala, sede de la Capitanía General y de la Audiencia, que contaba aproximadamente con 30,000 habitantes. En orden de importancia, le seguían San Salvador 20,000-, León -20,000-, Granada -10,000-y Cartago -9,000-..$^{43}$ En este contexto, Ciudad Real era una de las ciudades más pequeñas y con menor número de habitantes de todo el reino.

En las postrimerías del régimen colonial, a lo largo y ancho de Guatemala se respiraba una agobiante atmósfera de atraso y decadencia. En 1768 el arzobispo Pedro Cortés y Larraz, tras un largo recorrido por las provincias que integraban Guatemala, elaboró una Descripción geográfico-moral de la diócesis de Goathemala en donde se describen veredas estrechas, ciénegas en que las mulas se hundían hasta las cinchas, ríos acrecidos, tierras resbaladizas, maniguas impenetrables, desfiladeros peligrosos, callejones de peña, largas jornadas en que no se veían ni habitantes, ni sembrados, ni ganado, sino solamente bosques, montañas y ríos en lo profundo de los barrancos. En particular, el problema de la ausencia de vías de comunicación era tan grave que los curas no podían llevar la doctrina a muchos pueblos "porque los caminos eran intransitables o simplemente no los había". Los papeles oficiales [decretos, acuerdos, ordenanzas reales] solían demorarse semanas en llegar de una ciudad a otra. Gracias a la Descripción, nos enteramos de que grandes áreas del país permanecían despobladas hacia el tramo final del siglo XVIII, y que aquellas que no lo estaban se hallaban, en buena medida, aisladas. ${ }^{44}$

En la misma línea de Cortés y Larraz, José Bustamante y Guerra, quien asumió el cargo de Capitán General de Guatemala el 14 de marzo de 1811, explicaba así en su "Ofício al Consejo de Regencia"45 la situación del país:

Un área de 64 mil leguas cuadradas; yermos inmensos donde no se encuentra un solo pueblo. Caminos intransitables aún los de comunicación interior de un pueblo a otro. Los puertos en el mismo estado en que los formó la naturaleza. La capital, algunas villas y muchos pueblos, situados en puntos poco ventajosos para los progresos del giro [comercial]. La propiedad

\footnotetext{
${ }^{43}$ MARTínEZ PELÁEZ, Severo. (1988): "La Capitanía General de Guatemala. La tierra, los hombres, las comunicaciones", en COLLADO, Carmen; DUTRÉNIT, Silvia, et al.óp. cit,p. 72.

${ }^{44}$ CORTÉS Y LARRAZ, Pedro. (1958):Descripción geográfico-moral de la diócesis de Goathemala, hecha por su arzobispo, el ilustrísimo señor don Pedro Cortés y Larraz del Consejo de su Majestad. Guatemala. Biblioteca Goathemala / Sociedad de Geografía e Historia de Guatemala. Tomo 2.

${ }^{45}$ Consejo formado con la intención de preservar el poder de Fernando VII aún bajo la dominación napoleónica.
} 
territorial acumulada en pocas manos. El número de propietarios corto; grande proporcionalmente el de jornaleros y mayor el de vagos, ociosos o sin ocupación fija. La población muy mal distribuida. La riqueza estancada en pocos lugares, y el resto de los pueblos sumido en la mayor miseria. Las extracciones [transporte] de costo superior al que pueden sufrir los artículos de cultivo. La ciencia económica ignorada. Los conocimientos útiles poco difundidos; el sistema educativo ceñido a los de menor provecho. Los pueblos sin fondos para mejoras, y sus habitantes miserables o con pequeñas facultades para crearlos. Poco extendida la agricultura; obstruido el comercio; desalentada la industria. Así es como he encontrado un reino distinguido por la naturaleza en su situación, en la hermosura de sus campos, en la variedad de temperamento, diversidad de frutos y riquezas escondidas en su seno. ${ }^{46}$

En cuanto a la intendencia de Ciudad Real -que corresponde al actual estado de Chiapas-, se sabe que, conforme a la reordenación estipulada por la corona española bajo el gobierno ilustrado de los Borbones, fue establecida por Real Cédula del 20 de septiembre de 1786, y que aglutinaba los territorios de las alcaldías mayores de Tuxtla y Ciudad Real, así como la Gobernación de Soconusco. ${ }^{47}$

Chiapas se caracterizaba por su alto porcentaje de habitantes indígenas, en comparación al de mestizos o ladinos (en una relación de $80 \%$ contra $20 \%$ ), por lo que era considerada como la provincia más indígena de todas las que componían Guatemala. Además de su consustancial pobreza, la población de Chiapas sufría periódicamente de terribles epidemias, como una de tiña que se desarrolló en 1798 -y de la cual se habla incluso hasta 1811-, debido a la cual, afirmaba el Obispo Fermín José de Fuero, "la religión se va quedando sin prosélitos, el Estado sin vasallos, y estos feracísimos campos sin cultivadores, y sin habitantes. ${ }^{\circ 8}$

Sin embargo, Chiapas, tierra de contrastes, si bien ofrecía una cara de enfermedad y pobreza, mostraba también otra de abundancia. En una narración

\footnotetext{
${ }^{46}$ BUSTAMANTE Y GUERRA, José. (S. F.) Oficio al Consejo de Regencia, en Centroamérica en vísperas de la independencia, MARTÍNEZ PELÁEZ, Severo.Guatemala. Instituto de Investigaciones Sociales de la Universidad de San Carlos de Guatemala. p. 50.

${ }^{47}$ QUESADA, Flavio J. (1988): "El establecimiento de intendencias en la Capitanía General de Guatemala", en COLLADO, Carmen; DUTRÉNIT, Silvia, et al. óp. cit,p. 103.

${ }^{48}$ FUERO, Fermín José de. (1999): "Hospital de San Cristóbal L. C.”, Documento 19, en OROZCO Y JIMÉNEZ, Francisco. óp. cit.T. I.p. 77.
} 
anónima que Orozco y Jiménez sitúa en el siglo XVIII, la provincia es descrita del siguiente modo:

Tiene noventa y dos pueblos de indios naturales... Ciudad Real es ciudad corta y pobre... los frutos de la tierra son trigo, maiz, frijoles, algodón, cacao en alguna parte. Tiene muchas haciendas de ganado mayor y el carnero es muy rico. Ay en dicha provincia minas de plata, que no se trabajan por falta de caudales; y media legua distante de la ciudad ay una de diamantes... Ay varias hierbas medicinales y las que llaman piedras cuadradas, que sirven para varios remedios. Tiene varios rios... ${ }^{49}$

\section{La acción educativa desarrollada por la Corona en Chiapas a fines del Siglo XVIII y a comienzos del XIX}

A fines del siglo XVIII y a comienzos del XIX, la Corona española emprendió una afanosa empresa educativa en la Capitanía General de Guatemala, específicamente en la atrasada intendencia de Ciudad Real de Chiapas, orientada a fundar establecimientos escolares para enseñar las primeras letras, en particular en los pueblos indios, y que se proponía beneficiar también a los habitantes de los barrios indígenas en la propia Ciudad Real.

Pese a las dificultades que enfrentó el proyecto, en 1785 Ignacio de Coronado, Capitán del Regimiento de Dragones Provinciales de la capital del reino y justicia mayor de la provincia de Ciudad Real, suscribe a nombre del ilustrado Carlos III una "Instrucción que deberán observar todos los maestros proveídos para la enseñanza de la lengua castellana, leer y escribir en los pueblos de esta provincia" en donde indica en forma minuciosa el procedimiento que debían seguir los profesores desde su llegada al pueblo a que habían sido destinados.

Una vez acreditados por su respectivo título ante el cura del lugar, los maestros debían presentarse ante las autoridades para que éstas mandaran a los naturales que hicieran "venir diariamente a sus hijos, y demás muchachos indios que hayan, desde edad de cuatro o cinco años para arriba, y aún de menos edad si se pudiere, pues la experiencia nos enseña que aquellas cosas que aprendemos de chicos se nos imprimen mejor que cuando grandes". El documento estipula estrictamente que "para la escuela no se van a gravar a los naturales con raciones, salarios ni alimentos del Maestro, a excepción de las

\footnotetext{
${ }^{49}$ ANÓNIMO. (1999): "Documento del Fondo Gesuítico. 1255-3384, fasc. 30.”, en OROZCO Y JIMÉNEZ, Francisco. óp. cit.T. II. p. 22.
} 
cartillas, libros, papel, tinta y plumas que costearán en tiempo debido los padres de los mismos muchachos".

El lugar destinado para impartir las clases era la propia Casa Real, o bien el Cabildo, con un propósito didáctico: "como allí... concurren los naturales a sus negocios de Justicia, se logra el que todos oigan hablar lengua castellana, y vean practicar civiles y católicas costumbres". Los escolares asistirían de siete a once de la mañana, y de dos a cinco de la tarde. Las clases debían ofrecerse todos los días del año, a excepción de los domingos y días de fiesta; el sábado por la mañana, el maestro debía enseñar la doctrina cristiana, y poner a leer a los alumnos avanzados, para corregir la pronunciación, "procurando que no sea tanto lo que se lea, cuanto lo que se entienda", y con la advertencia de que, "cuando los indios pronunciasen alguna voz castellana, tosca y menos culta, no se ría ni los mofe, porque se avergonzarán y entibiarán en hacerse de la instrucción a que se aspira". Y aunque se ordenaba a los profesores que no consintieran en presencia de los alumnos que se pronunciaran "palabras torpes, murmuraciones, acciones indecentes", se recomendaba ante todo tratarlos "con amor y afabilidad, haciendo amable y no odiosa la enseñanza", y por ello mismo no se les debía injuriar, maltratar ni castigar en forma alguna. Se recomendaba también un método interesante y coloquial de aprendizaje: que cuando alguna persona visitara al maestro, estando éste en la escuela, el docente, en lugar de deshacerse de los alumnos, debía ordenarles que suspendieran cualquier otro trabajo que estuvieran haciendo, con el fin de que escucharan la conversación y aprendieran de ella, a la manera de testigos.

En cuanto al propósito ideológico -o cívico, según quiera verse- del centro escolar, la Instrucción señala:

Las intenciones de su Majestad se dirigen a que los indios aprendan la lengua castellana, leer y escribir, para que de esto provenga la buena crianza, y trato racional de gentes, y el perfecto conocimiento de la Ley, de lo que les resultarán muchos bienes, asi espirituales como temporales... Todos los días de la semana exercitará el maestro a los muchachos, en leer, y escribir, y con tesón infatigable, la lengua castellana, procurando que la hablen, y entiendan, y que se destruya el idioma que usan. Exortará y persuadirá que el que ellos no tengan la misma estimación y aprecio que los españoles, es por causa de que no hablan la lengua castellana, ni se enseñan a leer y escribir, y demás costumbres y civilización de la gente. ${ }^{50}$

\footnotetext{
${ }^{50}$ CORONADO, Ignacio de. (1785): “Instrucción que deberán observar todos los Maestros proveidos para la enseñanza de la lengua castellana, leer y escribir en los pueblos de esta provincia". 25 de mayo. Ramo VII, Educación.
} 
En cumplimiento de la Instrucción, y con el deseo de aliviar la miseria de los habitantes del pueblo de Teopisca, el obispo Francisco Javier de Olivares y Benito estableció en la localidad, en 1781, una escuela de enseñanza de hilados y tejidos, con sendos telares, dirigida a las jóvenes alumnas que previamente habían aprendido el castellano en la Doctrina. Al parecer la iniciativa tuvo éxito, pues acudían hasta cuarenta niñas indígenas para aprender a tejer, hilar y coser bajo la asesoría de dos maestras ladinas (mestizas) y un maestro de telas de la tierra. ${ }^{51}$

La fundación de la escuela no pasó entonces desapercibida para el Rey, pues éste mediante Real Cédula felicitó y agradeció los esfuerzos fundacionales del obispo. Con base en la anterior, el prelado aseguró, en un Reglamento que contenía doce artículos, ${ }^{52}$ que el centro educativo quedaba bajo la protección de la propia Corona, y establecía la normatividad necesaria para la operación del establecimiento. Según los artículos, las labores de las alumnas consistían en "desmotar algodón, hilar, devanar, hurdir y demás", bajo la dirección de la maestra respectiva. También asistirían hasta cuatro muchachos ladinos, a aprender a devanar, hurdir y tejer manta y nagua, bajo la dirección de un maestro. La Escuela recibió asimismo de la Corona un total de doscientos cinco pesos para la compra de materia prima, es decir algodones, y para el pago de los profesores. El obispo suponía que una vez que los alumnos hubieran adquirido cierta destreza, las utilidades por la venta de telas permitirían que la Escuela subsistiera con sus propios medios.

Siete años más tarde, en 1798, el obispo Fermín José Fuero dirigió una carta al Vicario General de la Orden de Predicadores, donde ponderaba "lo necesario que son en la República Cristiana las Escuelas de primeras letras", ${ }^{53}$ explicando que en la propia Ciudad Real no había sido abiertos estos centros educativos desde 1767, año de expatriación de los jesuitas, con excepción de uno que había en el Colegio Seminario, pero que resultaba insuficiente, pues si bien podían asistir a él los niños que vivían en el centro de la ciudad, no podían hacerlo los que habitaban en los barrios. ${ }^{54}$ Por este motivo, proponía crear una Escuela de Doctrina Cristiana en cada uno de los conventos de la población.

\footnotetext{
51 EL REY [Carlos IV]. (1792): "Real Cédula", en OROZCO Y JIMÉNEZ, Francisco. óp. cit. T. II, p. 219.1 de enero.

52 OLIVARES, Francisco Javier de. (1793): "Reglamento", en OROZCO Y JIMÉNEZ, Francisco. óp. cit. T. II, p. 220-221. 5 de enero.

53 FUERO, Fermín José. (1798): "El Ilmo. Señor Dr. Dn. Fermín Joseph Fuero Obispo de Chiapa y Soconusco, del Consejo de S. M. Católica sobre el establecimiento de tres escuelas públicas, y gratuitas de primeras letras en los Conventos de Santo Domingo, San Francisco y La Merced", en OROZCO Y JIMÉNEZ, Francisco. óp. cit. T. II, p. 201

${ }^{54}$ Los niños de los barrios no podían asistir a la Escuela del Seminario por la considerable distancia que tenían que recorrer, y por las copiosas lluvias que caen en la población durante buena parte del año. FUERO, Fermín José. (1799): "Carta al Dr. Castañares", en OROZCO Y JIMÉNEZ, Francisco. óp. cit. T. II, 207. 12 de marzo.
} 
Fuero logró convencer e incluso entusiasmar con su idea a los provinciales de Santo Domingo, San Francisco y la Merced. ${ }^{55}$ La favorable acogida que tuvo la iniciativa entre las órdenes religiosas que laboraban en Ciudad Real llevó al obispo a publicar un Edicto en donde anunciaba la apertura de tres casas de enseñanza en los Conventos de Santo Domingo, San Francisco y la Merced, a partir del 2 de enero de 1799. El Edicto invita a los padres y madres "a que tengáis sumo cuidado de que vuestros hijos entren a disfrutar, sin pérdida de tiempo, el singular beneficio de una buena educación". ${ }^{56}$

Para llevar a cabo su propósito, el obispo Fuero se dirigió a José Antonio Caballero, Ministro de Estado, y del Despacho de Gracia y Justicia, en una carta en la que solicitaba la protección especial del Estado, para asegurar de este modo la duración de las escuelas de primeras letras ya referidas, "que de otra suerte -escribe el Obispo- debía temerse que espirasen con mi muerte, o con mi ausencia". ${ }^{57}$ Aunque el ilustre religioso falleció el 14 de junio de 1800, antes de morir recibió un manuscrito firmado por el propio Rey, en donde éste aprobaba el establecimiento de las escuelas públicas ya referidas, y en el cual inclusose felicitaban sus esfuerzos:

Visto en mi Consejo de Indias... he resuelto... manifestaros la gratitud que me ha merecido este establecimiento... en consecuencia mando que en mi Real nombre se dé a entender a los tres mencionados Prelados, lo satisfecho que quedo por su celo; encargando el Presidente de Guatemala, y al Gobernador Intendente de esa provincia, estén a la mira de que los religiosos que se destinen para estos ministerios sean aptos y de arregladas costumbres... disponiendo que persuadan a los Padres de los niños a que los envien a las Escuelas... ${ }^{58}$

\section{La enseñanza de primeras letras Chiapas en los albores de la Independencia}

Durante la revolución de Independencia, a pesar de las vicisitudes y los enormes gastos a los que debía hacer frente la Corona española, el gobierno real siguió interesado en la fundación de escuelas de primeras letras. Cabe

\footnotetext{
${ }^{55} \mathrm{Al}$ parecer en La Merced no pudo abrirse una escuela debido a la escasez de personal de los mercedarios. FLORES RUIZ, Eduardo. (1978): La Catedral de San Cristóbal de las Casas. 1528-1978. Tuxtla Gutiérrez. Universidad Autónoma de Chiapas - Área de Humanidades. p. 109.

${ }^{56}$ FUERO, Fermín José. (1798): "Edicto", en OROZCO Y JIMÉNEZ, Francisco. óp. cit. T. II, 204. 24 de diciembre.

${ }^{57}$ FUERO, Fermín José. (1799): “Carta al Dr. Castañares”, en OROZCO Y JIMÉNEZ, Francisco. óp. cit. T. II, p. 207. 12 de marzo.

${ }^{58}$ EL REY [Carlos IV]. (1799): "Carta”. Ramo VII, Educación. 20 de diciembre.
} 
recordar que en 1813, en el marco de las Cortes de Cádiz, que habían sido convocadas por la Junta Suprema Central en España, se discutieron los temas de la educación y de los indígenas. En cuanto al primer punto, se decidió que todos los pueblos debían tener escuelas donde los niños aprendieran a "leer, escribir y contar", y estudiaran el catecismo de la religión católica, el cual incluía una breve exposición de las obligaciones civiles. ${ }^{59}$ Respecto a los indígenas, los diputados coincidieron en que éstos eran americanos olvidados, y que las condiciones miserables en que habían vivido siempre debían ser mejoradas, dado que la Corona los había conservado en el atraso y la ignorancia.

Cuando en 1814 Fernando VII retomó las riendas del gobierno español y declaró "nulos y de ningún valor ni efecto" la Constitución de 1812 y los decretos emanados de las Cortes, siguió empleando empero a un buen número de pensadores que habían participado en ellas. ${ }^{60}$ De esta manera, el rey español mantuvo durante algunos años una visión más abierta y menos conservadora de lo que comúnmente se cree, influenciada por ejemplo, en el terreno educativo, por ideas de pensadores tan notables como Benito Jerónimo Feijoo. En este contexto se ubican los esfuerzos de la Corona por fundar escuelas de primeras letras, incluso durante los últimos años del régimen colonial. En 1817, por ejemplo, el Rey explica en un Decreto que el Cardenal Patriarca de las Indias ha pedido a la Santa Sede "que conceda a los Arzobispos, Obispos, y otros Prelados de sus reinos, que tienen jurisdicción sobre los monasterios de monjas, las facultades oportunas para que puedan establecer escuelas para niñas en todos los lugares y monasterios". ${ }^{61}$

En opinión del Rey, la formación de "escuelas caritativas de primera educación" constituía el medio más adecuado para evitar que desde temprana edad, los niños se aficionaran a la vida "ociosa y vagamunda", y para que, por el contrario, formaran parte de la clase de "súbditos trabajadores y útiles al Estado". En cuanto a la propuesta, y debido a que el Real Erario se hallaba en dificultades, instruía a los Conventos de todas las órdenes religiosas a abrir los nuevos centros educativos, cuya obligación sería propagar "el conocimiento de la religión y la enmienda de las costumbres".

La respuesta que da al obispo Samartín el Provincial de la Orden de Predicadores, Matías de Córdova, en 1817, respecto a la iniciativa del Rey, es

\footnotetext{
${ }^{59}$ RODRÍGUEZ, Mario. (1984): El experimento de Cádiz en Centroamérica, 18081826.México: Fondo de Cultura Económica. p. 116.

${ }^{60}$ Ibídem, p. 170.

${ }^{61}$ EL REY [Fernando VII]. (1817): "Decreto". Ramo VII, Educación. 20 de octubre.
} 
entusiasta, aunque al mismo tiempo no deja de ser realista. Explica, por ejemplo, que tanto en el Convento de Ciudad Real como en el de Comitán ya se hallan abiertas escuelas de Doctrina Cristiana y primeras letras; sin embargo, añade que en los Conventos de Chiapa y Tecpatán aquellas no han podido establecerse, "porque habiéndose arruinado los conventos, no hay pieza para que asistan los niños, y es menester aguardar a la reedificación de uno y otro convento, que se emprenderá luego que cesen las aguas." ${ }^{2}$

Pese a las dificultades a las que hace mención Matías de Córdova, el Obispo Samartín trata de cumplir con la encomienda real. Por eso le pide al Provincial de la Orden de Predicadores que comunique la orden a los padres priores de los Conventos de su orden fundados en los pueblos de Comitán, Chiapa y Tecpatlán, y al de la propia Ciudad Real, "a efecto de que a la mayor posible brevedad, procedan a entablar las Escuelas de primera educación, donde se deberán instruir en la Doctrina Cristiana, en las buenas costumbres y en las primeras letras, principalmente a los hijos de los pobres, hasta la edad de diez o doce años." ${ }^{63}$ A su vez, Sor María de la Merced Domínguez, Abadesa del Convento de Monjas de Nuestra Señora de la Encarnación, pide al Obispo Samartín que, en acatamiento de la Real Cédula, dispense la clausura del establecimiento religioso, con el fin de que las niñas puedan entrar y salir de éste cuando concurran a instruirse.

"A pesar de que somos tan pocas -escribe-, pues todo el número de religiosas sólo llega a diez y seis, de las cuales están imposibilitadas algunas por su edad avanzada... queda todo dispuesto para que se dé principio a la escuela el día que V. S. Yltma. Lo disponga." ${ }^{64} \mathrm{El}$ mismo entusiasmo conduce incluso al Obispado, en 1919, a la adquisición de una casa, que se ha destinar a la erección de una Escuela Pública de primera educación para niñas, cuyo profesor proviene de la capital de Guatemala. ${ }^{65}$

Sin embargo, en contraste con la iniciativa real y las buenas intenciones de los religiosos, la situación de los profesores por lo general debió ser angustiosa, como se puede ver en la comunicación que dirige a las autoridades en 1820 Francisco Paniagua, profesor de la Escuela de primeras letras de Ciudad Real,

\footnotetext{
${ }^{62}$ CÓRDOVA, Fr. Matías de. (1817): "Manuscrito". Ramo VII, Educación. 7 de septiembre.

${ }^{63}$ SAMARTÍN, Salvador. (1818): "Carta dirigida a Sor María de la Merced Domínguez".

Ramo VII, Educación. 6 de agosto.

${ }^{64}$ MERCED DOMÍNGUEZ, Sor María de la. (s. f.): "Carta a Dn. Salvador Samartín".

Ramo VII, Educación.

${ }^{65}$ SAMARTÍN, Salvador. (1819): "Carta”. Ramo VII, Educación. 13 de agosto.
} 
Morelos Torres Aguilar

para pedir un aumento de salario. "Hace algunos años - escribe- que sirvo a la Escuela con el diminuto salario de diez pesos cada mes... teniendo que solicitar mi sustentación por distinto camino a causa de la escasa contribución... ni se puede de otra suerte servir siendo tan crecido el número de niños que asisten en estos tiempos, son más de ciento". ${ }^{66}$

Es muy probable que la gran mayoría de los profesores asignados a las escuelas de primeras letras sufrieran la misma situación desesperada, consistente en bajos sueldos, numerosos alumnos y grandes trabajos.

\section{El fracaso de la enseñanza de primeras letras en Chiapas en los albores de la Independencia}

En buena medida, los esfuerzos de la Iglesia de fundar y hacer funcionar escuelas de primeras letras en Chiapas en las postrimerías del régimen colonial fueron estériles. Durante los primeros años del México independiente, la crónica falta de recursos, el desorden de los municipios, la incapacidad de las autoridades para hacer cumplir las leyes, así como los acendrados usos y costumbres de los pobladores de la provincia, impidieron la realización del proyecto educativo de la Corona y de la Iglesia.En los "Informes de los párrocos del Estado al Gobierno del mismo, sobre la situación de los pueblos...", dados en cumplimiento de una orden Circular de fecha 23 de junio de 1830, veintiún párrocos a cargo de otros tantos curatos, parroquias y vicarías de Chiapas expresan, generalmente con gran desaliento, las dificultades a que se han visto enfrentados para proporcionar instrucción a los niños y los jóvenes habitantes de los pueblos y villas en los que desarrollan su labor pastoral y educativa. ${ }^{67}$

Los ejes principales sobre los que se conduce la visión crítica de los religiosos en sus respectivos informes, son tres: la parálisis de los ayuntamientos y la imposibilidad de aplicar las leyes; los usos y costumbres - pero sobre todo los vicios- de los pobladores; y finalmente, el mal estado de la instrucción y la educación en los pueblos y ciudades de la provincia. Cabe destacar que uno de los factores más importantes para entender el considerable atraso de la sociedad chiapaneca en el siglo XIX, es el alcoholismo que hacía presa de buen número de habitantes de la provincia. El abuso en el consumo del aguardiente constituía un pesado lastre para la población.

\footnotetext{
${ }^{66}$ PANIAGUA, Francisco. (1820): “Carta al Provisor y Vicario General”. Ramo VII, Educación. 18 de agosto.

67 "Informes de los párrocos del Estado al Gobierno del mismo, sobre la situación de los pueblos, dados en cumplimiento de la orden circular de 23 de junio de 1830". (1830), en OROZCO Y JIMÉNEZ, Francisco. óp. cit. T. II, p. 106.
} 
Sobre el tema específico de la educación, los religiosos manifestabanen los Informes que hasta esa fecha, muchos indígenas sencillamente no entendían el castellano, y que apenas unos pocos de ellos asistían a la enseñanza de la doctrina cristiana; o bien, que los naturales carecían "de todo principio de enseñanza", es decir, de toda instrucción. Los párrocos explicaban también que en la mayor parte de las poblaciones se carecía de escuela, sin que el ayuntamiento hubiera podido construirla, por carecer de fondos; y que los pocos habitantes que podían proporcionar instrucción, no lo hacían. El problema del analfabetismo era tan grave, que fray Eugenio de Córdova, cura de Zocoltenango, refiere en el documento, por ejemplo, que "en todo el pueblo no hay ocho individuos de catorce a diez y seis años que sepan leer".

En general, el principal problema que exhiben los informes es la carencia de escuelas de primeras letras en los pueblos referidos. La única educación que se proporcionaba a los indígenas consistía en algunas lecciones de dogma y moral, a las que la inmensa mayoría de los niños y jóvenes no acudía. Y si a esto se suma la indiferencia con que los indígenas miraban la enseñanza, se tendrá una idea del desalentador estado en que se encontraba la educación de primeras letras en los albores de la independencia en Chiapas.

\section{CONCLUSIONES}

Como se puede ver mediante los ejemplos presentados, en el ámbito de la Nueva España o el de la Capitanía General de Guatemala, la enseñanza de primeras letras siguió un derrotero menos progresista que los casos observados en la península ibérica. Si bien fueron fundadas en las dos vastas colonias escuelas de primeras letras, como ya se ha visto, éstas no fueron instauradas por los escolapios -y por tanto no fue posible aprovechar en ellas toda la experiencia acumulada por éstos durante cerca de dos siglos, ni fueron producto de agrupaciones ilustradas como las Sociedades de Amigos del País.

Por otra parte, muchos de los problemas que impidieron el desarrollo cabal de las escuelas de primeras letras a lo largo de los dilatados dominios de la Corona eran los mismos, trascendían las regiones a finales del siglo XVIII y a principios del XIX. Tanto en Navarra como en Murcia, tanto en Almería como en Cataluña, tanto en Yucatán como en Chiapas, escaseaban los maestros, o si los había, posiblemente no tenían la preparación adecuada; no había suficientes escuelas para responder a las necesidades de la población estudiantil, y si las había, solían carecer de la infraestructura física adecuada para la impartición de clases; los salarios que recibían los docentes eran tan raquíticos, que obligaban a que éstos redondearan sus ingresos con el ejercicio de una segunda profesión 
u oficio; finalmente, a todo lo largo de los dominios de España el Estado no financiaba en forma adecuada el ramo educativo.

Tanto en España como en América, según los ejemplos mostrados, los alumnos de primeras letras solían faltar a clases debido a que trabajaban en las labores del campo, o bien por la negligencia de los padres, a quienes no les interesaba que los hijos se instruyeran, pues la población solía considerar que los conocimientos adquiridos en una escuela de este nivel no eran necesarios, o por lo menos, que no resultaban indispensables.

Ahora bien, la mayor diferencia entre las escuelas de primeras letras establecidas a una y otra orillas del Atlántico reside en un hecho fundamental. En España, las escuelas enseñaban a los alumnos una lengua que ya conocían, pues estaba compuesta de las palabras que se pronunciaban en sus casas. En cambio, en provincias como Yucatán o precisamente Chiapas, donde la mayor parte de los alumnos eran indígenas, éstos no se identificaban con la lengua castellana, porque no era el lenguaje en que se comunicaban sus hermanos y sus padres. Sencillamente, no era el lenguaje que acostumbraban, siendo la costumbre uno de los factores más importantes para la existencia de los nativos.

Este factor representó en buena medida un problema insalvable. Los indígenas veían en el idioma castellano un instrumento extraño, ajeno, y muchas veces innecesario. Tampoco pensaban que su aprendizaje sirviera para mejorar su condición social. De este modo, las escuelas de primeras letras estaban condenadas de antemano al fracaso, por el desinterés de los futuros alumnos y la indiferencia o hasta la aversión de los padres de familia, incluso antes de que el maestro impartiera en ellas su primera clase.

Se puede aventurar para explicar este hecho una explicación de carácter histórico. Durante los dos primeros siglos de la colonia, en provincias como Chiapas, los religiosos habían concentrado sus esfuerzos en evangelizar a los naturales; para ello habían aprendido las lenguas nativas, y se habían servido de ellas con el fin de enseñar la doctrina en la propia lengua de los indígenas. De esta manera, cuando en el siglo XVIII la Corona decidió castellanizar a sus súbditos en Chiapas, el rezago que estos pueblos habían acumulado en el aprendizaje del idioma era palpable. Durante más de doscientos años, no se les había enseñado a los pueblos originarios el idioma de los españoles en forma sistemática; ahora era demasiado tarde para retomar la ardua tarea.

En suma, en los albores de la etapa independiente, la intendencia de Ciudad Real de Chiapas presentaba un panorama desalentador en el ámbito educativo. A 
diferencia de lo que ocurría en España, no había otra institución más que la Iglesia que llevara a cabo el propósito de castellanizar, siquiera en forma rudimentaria, a los pobladores. Y aunque la enseñanza de primeras letras en la entidad se podía equiparar a la de alguna zona rural de la península ibérica, la extrema pobreza de sus habitantes, y la ineficacia de las autoridades, difícilmente podía ser igualada. En este contexto, el discurso educativo de los ilustrados no pudo penetrar, en la aislada provincia centroamericana, la dura coraza de la ignorancia, hecho que preservó la desigualdad, aún superada la larga etapa colonial.

\section{FUENTES}

\section{ARCHIVO HISTÓRICO DIOCESANO DE SAN CRISTÓBAL DE LAS CASAS. (AHDSCLC)}

San Cristóbal de las Casas, Chiapas, México.

Ramo VII. Educación.

CORONADO, Ignacio de. (1785): “Instrucción que deberán observar todos los Maestros proveidos para la enseñanza de la lengua castellana, leer y escribir en los pueblos de esta provincia”. 25 de mayo. Ramo VII, Educación.

EL REY [Carlos IV]. (1799): “Carta”. Ramo VII, Educación. 20 de diciembre.

EL REY [Fernando VII]. (1817): "Decreto". Ramo VII, Educación. 20 de octubre.

CÓRDOVA, Fr. Matías de. (1817): “Manuscrito”. Ramo VII, Educación. 7 de septiembre.

SAMARTÍN, Salvador. (1818): "Carta dirigida a Sor María de la Merced Domínguez". Ramo VII, Educación. 6 de agosto.

MERCED DOMÍNGUEZ, Sor María de la. (s. f.): "Carta a Dn. Salvador Samartín”. Ramo VII, Educación.

SAMARTÍN, Salvador. (1819): “Carta”. Ramo VII, Educación. 13 de agosto.

PANIAGUA, Francisco. (1820): "Carta al Provisor y Vicario General". Ramo VII, Educación. 18 de agosto.

\section{REFERENCIAS}

ALEGRE, Francisco Javier. (1842): Historia de la Compañía de Jesús en Nueva España. Publicada por Carlos María de Bustamante. México. J. M. Lara. Tomo II.

ALFREDO HERRERA, Sajid. (2007): "PrimaryEducation in Bourbon San Salvador and Sonsonate, 1750-1808", en DYM, Jordana; BELAUBRE, Christophe (Coord.) Politics, economy, and society in Bourbon Central America, 1759-1821. University Press 
of Colorado. pp. 17-46.

CARVALHO, Alma Margarita. (1994): La Ilustración del Despotismo en Chiapas, 17741821. México. Consejo Nacional para la Cultura y las Artes.

DELGADO CRIADO, Buenaventura (Coord.). (1994): Historia de la educación en España y América. Volumen 3. La educación en la España contemporánea (17891975).Madrid. Ediciones SM / Fundación Santa María.

FLORES RUIZ, Eduardo. (1978): La Catedral de San Cristóbal de las Casas. 15281978. Tuxtla Gutiérrez. Universidad Autónoma de Chiapas - Área de Humanidades.

GUTIÉRREZ BARBA, Alfonso. (2001): "Situación de la enseñanza de primeras letras en la comarca de Tentudía entre mediados del siglo XVIII y mediados del XIX", en Actas del I Congreso de la Memoria Colectiva de Tentudía. Badajoz. Centro de Desarrollo Comarcal de Tentudía.

GUTIÉRREZ CRUZ, Sergio Nicolás. (2004): "Reflexiones sobre la independencia de la provincia chiapaneca y su integración a México", en Ibarra, Ana Carolina (Coord.), La independencia en el sur de México. México, Universidad Nacional Autónoma de México - Facultad de Filosofía y Letras, Instituto de Investigaciones Históricas.

MANGUEN, Jaime; MONTESINOS, Irma. (1981): Historia de la educación en Chiapas. San Cristóbal de las Casas. Universidad Autónoma de Chiapas.

MARTÍNEZ PELÁEZ, Severo. (1988): "La Capitanía General de Guatemala. La tierra, los hombres, las comunicaciones", en COLLADO, Carmen; DUTRÉNIT, Silvia, et. al. Centroamérica I. México. Secretaría de Educación Pública / Instituto Mora / Universidad de Guadalajara. pp. 67-74.

MARTÍNEZ PELÁEZ, Severo. (1998): La patria del criollo. Ensayo de interpretación de la realidad colonial guatemalteca. México. Fondo de Cultura Económica.

MÉNDEZ PEREIRA, Octavio. (1999): Historia de la Instrucción Pública en Panamá. Panamá. Autoridad del Canal de Panamá. [Se publica junto con MOSCOTE, José Dolores. Itinerario: selección de discursos, ensayos y conferencias]

MENESES MORALES, Ernesto. (1988): Tendencias educativas oficiales en México. 1821-1911. México. Universidad Iberoamericana / Centro de Estudios Educativos.

OROZCO Y JIMÉNEZ, Francisco. (1999): Documentos Inéditos de la Historia de la Iglesia en Chiapas. Tuxtla Gutiérrez. Gobierno del Estado de Chiapas / Consejo Estatal para la Cultura y las Artes de Chiapas. Tomos I y II.

ORTIZ HERRERA, Rocío. (2003): Pueblos indios, iglesia católica y élites políticas en Chiapas (1824-1901). Una perspectiva comparada. Tuxtla Gutiérrez. Consejo Estatal para la Cultura y las Artes de Chiapas / El Colegio de Michoacán.

PÉREZ SALAS, Ma. Esther; Guillén, Diana. (1994): Chiapas, una historia compartida, 
México, Instituto de Investigaciones Dr. José María Luis Mora.

PÉREZ DE LOS REYES, Marco A. (1988): "Fray Matías de Córdova. Su vida y su obra", en Memoria del IV Congreso de Historia del Derecho. México. Universidad Nacional Autónoma de México-Instituto de Investigaciones Jurídicas. Tomo II.

QUESADA, Flavio J. (1988): "El establecimiento de intendencias en la Capitanía General de Guatemala", en COLLADO, Carmen; DUTRÉNIT, Silvia, et. al. Centroamérica I. México. Secretaría de Educación Pública / Instituto Mora / Universidad de Guadalajara.

RODRÍGUEZ, Mario. (1984): El experimento de Cádiz en Centroamérica, 1808-1826. México. Fondo de Cultura Económica.

SANTIAGO CRUZ, Francisco. (1977): Breve historia del Colegio de la Compañía de Jesús de Ciudad Real de Chiapas. México. Editorial Tradición.

TRENS, Manuel B. (1957): Bosquejos históricos de San Cristóbal de las Casas. México. (S.E.)

TANCK DE ESTRADA, Dorothy. (1996): "Enseñanza y nacionalismo intelectual al final de la colonia", en BAZANT, Milada (Coord.): Ideas, valores y tradiciones. Ensayos sobre historia de la educación en México. México. El Colegio Mexiquense.

TRENS, Manuel B. (1999): Historia de Chiapas. Desde los tiempos más remotos hasta la caída del Segundo Imperio (¿...1867?). Tuxtla Gutiérrez, Consejo Estatal para la Cultura y las Artes de Chiapas - Libros de Chiapas. Tomos I y II.

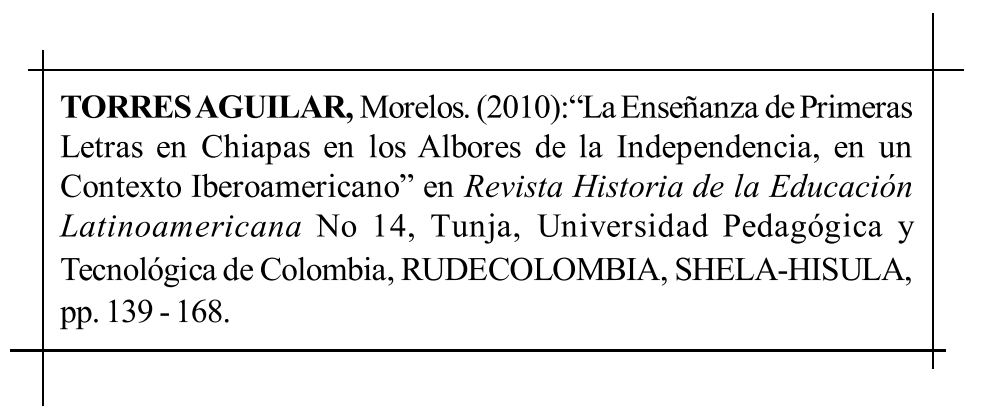

Rhela. Vol. 14. Año 2009, pp. 139 - 168 